tativa da articulação temporomandibular o que potencia a ocorrência de distúrbios temporomandibulares (DTM) em idosos. Uma das principais manifestações dos DTM é a dor muscular e/ou articular pelo que o objetivo deste estudo passa pela avaliação desta sintomatologia numa população geriátrica institucionalizada. Materiais e métodos: A amostra engloba 63 indivíduos geriátricos (44 mulheres e 19 homens) com idade compreendida entre os 60 e os 99 anos e residentes em Viseu, mais concretamente, no Lar Viscondessa São Caetano e no Centro Social Paroquial Rio de Loba. Este estudo observacional transversal, através da aplicação do Questionário Anamnésico da Fonseca (QAF) e do Índice de Helkimo (IH), consiste numa pré-seleção dos indivíduos com manifestações dolorosas na região da ATM aos quais é posteriormente aplicado o RDC/TMD (Research diagnostic criteria to temporomandibular disorders) e interpretado o seu Eixo I para objetivar o diagnóstico. Respeitando todos os requisitos éticos e de confidencialidade, os dados foram introduzidos e analisados no IBM SPSS Statistics ${ }^{\circledR}$ com o limiar de significância estatística de 5\%. Resultados: Dos 63 indivíduos avaliados segundo o QAF 17,5\% ( $\mathrm{n}=11)$ apresentava dor e cansaço muscular e 30,2\% (n=19) possuía dor na ATM. Pela aplicação do IH, 26,98\% ( $n=17)$ dos idosos manifestava dor muscular enquanto que $19,05 \%(n=12)$ apresentava dor articular. O RDC/TMD foi aplicado somente aos 23 indivíduos com respostas afirmativas no IH e/ou QAF, isto é, aqueles que apresentaram sintomatologia característica dos DTM. De acordo com esta ferramenta, 34,8\% (n=8) exibia dor articular à palpação ao nível do polo lateral do côndilo mandibular e $13,04 \%(n=3)$ ao nível da inserção posterior articular. Por sua vez, a maioria dos indivíduos, 65,2\% ( $n=15)$, apresentava dor muscular à palpação, sendo que destes 34,8\% (n=8) manifestavam sensação dolorosa em 1 a 3 locais palpados e 30,4\% $(n=7)$ em mais do que 3 locais. Conclusões: Dada a subvalorização dos sintomas orofaciais nos indivíduos geriátricos e uma vez que na população estudada se verificou uma elevada predominância de dor muscular e articular, é fundamental a elaboração de mais investigações no âmbito da caracterização dos DTM nesta faixa etária para planear estratégias no foro da saúde orofacial e potenciar avanços quanto à abordagem terapêutica destes indivíduos em prol da melhoria da qualidade de vida.

http://doi.org/10.24873/j.rpemd.2019.12.619

\#162 A relação das má-oclusões com as desordens temporomandibulares

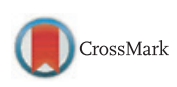

Ana Rita Oliveira*, Patricia Fonseca, Rita Carvalho, Susana Silva

Instituto de Ciências da Saúde, Viseu - Universidade Católica Portuguesa, Centro de Investigação Interdisciplinar em Saúde (CIIS) - Universidade Católica Portuguesa, Viseu

Objetivos: Esta investigação tem como objetivo principal procurar uma relação entre as má-oclusões e as desordens da articulação temporomandibular em alunos do Mestrado Integrado em Medicina Dentária do Instituto de Ciências da Saúde da Universidade Católica Portuguesa. Materiais e métodos: Trata-se de um estudo observacional descritivo-transversal, realizado num momento observacional único. Cada paciente que consente participar no estudo é observado pela investigadora que recolhe os dados através das análises cefalométricas de Ricketts, Steiner e WITS, da análise de modelos ortodônticos, do questionário adaptado e do exame clínico do CDP/DTM e do eixo I dos Critérios de Diagnóstico para Pesquisa de Disfunções Temporomandibulares. Para o tratamento estatístico dos dados recolhidos utilizou-se o programa SPSS ${ }^{\circledR}$ com um limiar de significância estatística de 5,0\%. Resultados: Perante os tipos de má-oclusão avaliados neste estudo, apenas a relação molar direita ( $p=0,005)$, a discrepância dento-maxilar inferior $(p=0,049)$ e os três tipos de padrões de crescimento esquelético avaliados segundo as análises cefalométricas de Ricketts $(p=0,017)$, Steiner $(p=0,014)$ e WITS $(p=0,032)$ demonstraram ter uma associação estatisticamente significativa relativamente ao grupo III da articulação temporomandibular direita do eixo I dos Critérios de Diagnóstico para Pesquisa de Disfunções Temporomandibulares. A discrepância dento-maxilar mandibular ( $p=0,038)$ também demonstrou ter uma relação de dependência com o grupo II da articulação temporomandibular esquerda do eixo I dos Critérios de Diagnóstico para Pesquisa de Disfunções Temporomandibulares. Conclusões: Existe uma associação estatisticamente significativa entre alguns tipos de má-oclusão e as desordens temporomandibulares, contudo, estes resultados não refletem a tendência da totalidade da população portuguesa, sendo importante realizar estudos mais abrangentes da população em geral. http://doi.org/10.24873/j.rpemd.2019.12.620

\section{\#163 Alterações na ATM em Doente Classe II Esquelética Submetidos a Cirurgia Ortognática}

Adriana Guimarães*, Inês Francisco, Isabel Amado, Francisco Caramelo, Francisco do Vale

Institute of Clinical and Biomedical Research University of Coimbra, Institute of Orthodontics, Faculty of Medicine, University of Coimbra, Department of Maxillofacial Surgery - Coimbra University Hospital Centre

Objetivos: A osteotomia sagital bilateral (BSSO) é comumente considerada a técnica cirúrgica de eleição para o tratamento da classe II esquelética. Após a cirurgia ortognática, a reabsorção condilar, pode afetar a articulação temporomandibular(ATM), ocasionando em alguns casos recidiva cirúrgica. O objetivo é realizar uma meta-análise para avaliar se a BSSO em pacientes com classe II esquelética resulta em disfunção temporomandibular determinada pela reabsorção condilar. Materiais e métodos: A pesquisa bibliográfica foi realizada na PubMed, Web of Science, Cochrane Library, Google Scholar e Embase, incluindo-se revisões sistemáticas em inglês de janeiro de 2007 até março de 2019, realizadas em doentes com classe II esqueléticas com idade superior a 18 anos submetidos a BSSO de avanço mandibular. Na pesquisa electrónica foram identificadas 908 publicações. Quatro publicações cumpriram os critérios de inclusão e foram incluídas nesta meta-análise. A avaliação qualitativa dos estudos seleccionados foi realizada utilizando a lista de verificação Assessment of Multiple Systematic Reviews - AMSTAR 2. Resultados: Quatro revisões siste- 